\title{
THE CONCENTRATION OF AFFLUENCE IN THE UNITED STATES, 1990
}

\author{
CRAIG ST. JOHN \\ University of Oklahoma
}

\begin{abstract}
The author examines the concentration of affluent households in affluent neighborhoods in U.S. metropolitan areas in 1990. The rate of concentrated affluence, the percentage of affluent households living in affluent neighborhoods, is considered for the total population and separately for blacks and whites. Also, differences in the rate of concentrated affluence between blacks and whites are explored. Models of concentrated affluence that incorporate variables suggested by the literature on economic restructuring in the late twentieth century and by the literature on racial differences in the residential return to individual resources are developed and tested. In general, variables measuring industry/occupation employment mix influence the rate of concentrated affluence mainly through the levels of income they generate. Racial differences in the rate of concentrated affluence are influenced more by income differences between blacks and whites than by residential segregation.
\end{abstract}

Ever since Wilson (1987) published The Truly Disadvantaged, researchers have been concerned with the geographic distribution of urban poverty (Jargowsky 1997; Kasarda 1993; Krivo et al. 1998; Krivo and Peterson 2000; Massey and Denton 1993; Wilson 1996). In contrast, they have paid little attention to the geographic distribution of urban affluence. Massey (1996) has noted that just as the geographic concentration of poverty contributes to the geographic concentration of problems associated with poverty, the geographic concentration of affluence compounds the advantages of affluence. Furthermore, to the extent the affluent live in neighborhoods or communities inhabited by others who also are affluent, they have limited political or social interest in dealing with the problems of those who are less fortunate. Accordingly, Massey suggested that if we are to understand a world of increasing segregation by economic status, then we must study the world of the affluent as well as the world of the poor. This study contributes to this goal by (1) examining differences among U.S. metropolitan areas in the extent to which affluent households live in neighborhoods where most of the neighboring

URBAN AFFAIRS REVIEW, Vol. 37, No. 4, March 2002 500-520

(C) 2002 Sage Publications 
households also are affluent (i.e., the "concentration of affluence") and (2) examining differences between blacks and whites in the concentration of affluence.

\section{INCOME INEQUALITY AND THE CONCENTRATION OF AFFLUENCE}

Although no body of research deals specifically with explaining variation among metropolitan areas in the concentration of affluence, the literature on recent increases in income inequality suggests that it can be explained by differences in economic structures and their resulting income distributions. Since the early 1970s, income inequality has increased in the United States (Levy 1995), with the relative incomes of the wealthiest families increasing and the relative incomes of the poorest families decreasing (Danziger and Gottschalk 1995). The middle class has become smaller and the extremes of the income distribution have grown larger (Morris, Bernhardt, and Hancock 1994). Massey (1996) attributed rising income inequality to broad trends characteristic of a postindustrial order. These trends resulted in the declining significance of heavy manufacturing in the U.S. economy (Kasarda 1995) and the increasing significance of employment involving the manipulation of capital (Sassen 1991). Durable goods manufacturing provides for a broad middle class with relatively little income inequality (Maddrick 1995). In contrast, nondurable goods manufacturing, much of which is done by low-skilled, poorly paid workers, contributes to income inequality (Reich 1989). Furthermore, employment based on manipulating capital increases income inequality by funneling income toward those with the requisite knowledge and skills and creating a large class of workers who provide cheap labor for those more central to the flow of capital (Reich 1989; Sassen 1991). Sassen (1991) argued that the process leading to increasing income inequality has had a spatial component. It has not occurred equally among U.S. cities but has been concentrated in large cities, especially New York City, that are oriented toward global finance. It is within such cities that the bifurcation of income is greatest. As a consequence, these cities have the greatest potential for economic residential segregation and the concentration of affluence.

This line of reasoning leads to the following hypotheses. The concentration of affluent households into affluent neighborhoods should be greatest in metropolitan areas with economic bases most closely reflecting the economic restructuring described earlier. This relationship should be indirect, operating through the level of income inequality and the economic residential segregation associated with a particular form of economic activity. Where 
income is most concentrated among affluent households, affluent households should be best able to segregate themselves from others and live in neighborhoods composed mostly of other affluent households. Specifically, durable goods manufacturing employment should be negatively related to the concentration of affluence. It produces little income inequality, limiting the ability of affluent households to segregate themselves from others and thus reside in neighborhoods consisting mostly of other affluent households. Conversely, nondurable goods manufacturing employment and professional, managerial, and technical employment, the latter representing the skill and knowledge base central to the flow of capital, should be positively related to the concentration of affluence. The income inequality they create enhances the ability of affluent households to segregate themselves from others and to reside in neighborhoods where most of the other households also are affluent.

It is likely that the effect of income inequality on economic segregation and, hence, the concentration of affluence depends on the mean household income of a metropolitan area. In poor metropolitan areas, income inequality is less likely to result in a substantial number of affluent households with the ability to segregate themselves from others than it is in affluent metropolitan areas. That is, in poor metropolitan areas, the concentration of income among the better off households does not necessarily result in those households being exceptionally affluent or even affluent at all. But in affluent metropolitan areas, the concentration of income among the better off households does.

\section{RACIAL DIFFERENCES IN THE CONCENTRATION OF AFFLUENCE}

A substantial literature indicates that the residential location process works differently for blacks compared to whites, attributing such differences to high levels of racial residential segregation (Massey and Denton 1993). For example, several studies have shown that blacks get less return in residential quality for their socioeconomic resources than do whites (Alba and Logan 1991, 1993; Alba, Logan, and Bellair 1994; Logan, Alba, and Leung 1996). For example, blacks tend to live in communities with lower median household incomes than whites, even after differences in individual characteristics such as income are taken into account (Logan and Alba 1993, 1995; Logan et al. 1996). These studies imply that affluent black households are less likely to live in affluent neighborhoods than affluent white households. But they are inconclusive because they do not actually examine the likelihood of affluent households of either race living in affluent communities. Furthermore, they 
do not explicitly consider racial residential segregation as an explanatory variable.

In this article, I examine the hypothesis that racial residential segregation influences the concentration of black and white affluent households into affluent neighborhoods and racial differences in the concentration of affluence. In most metropolitan areas, there are relatively few black affluent households compared to the number of white affluent households. Short of nearly all black affluent households living in the same neighborhoods, if black affluent households are to live in affluent neighborhoods, they must live in neighborhoods with white affluent households. Thus, the greater the segregation of black and white affluent households, the less likely black affluent households are to live in affluent neighborhoods. On the other hand, segregation between black and white affluent households should have little bearing on the concentration of affluence for whites. Because there are sufficient numbers of white affluent households from which to form affluent neighborhoods, white affluent households are not dependent on living with black affluent households for access to affluent neighborhoods. Although segregation between black and white affluent households should have little effect on the concentration of affluence for whites, it is likely that black-white segregation, in general, does. Because, on average, blacks have lower incomes than whites, racial segregation should contribute to the neighborhoods in which whites live being more affluent, increasing the opportunity for white affluent households to live in affluent neighborhoods. To the extent racial residential segregation influences the concentration of black and white affluent households into affluent neighborhoods, it also should influence black-white differences in the concentration of affluence. By decreasing the concentration of affluence for blacks, segregation between black and white affluent households should be positively related to black-white differences in the concentration of affluence. By increasing the concentration of affluence for whites, segregation between blacks and whites, in general, also should be positively related to black-white differences in the concentration of affluence.

\section{DATA AND MEASUREMENT}

The units of analysis in this research are the 335 metropolitan statistical areas (MSAs) defined for the 1990 census. When a metropolitan area is part of a consolidated metropolitan statistical area, primary metropolitan statistical areas are used. All data come from summary file three for the 1990 census. 
There is not an established procedure for measuring the concentration of affluence. A number of studies have examined a related topic, economic residential segregation, using well-known segregation indices (Abramson, Tobin, and VanderGoot 1995; Jargowsky 1996; Massey and Eggers 1993; Massey 1996). These indices are summary measures of the distribution of families or households with different incomes into neighborhoods. They tell us little about the distribution of affluent households into affluent neighborhoods. Neither Abramson, Tobin, and VanderGood (1995) nor Jargowsky (1996) explicitly consider an affluent population in their studies, and none of them attempt to identify affluent neighborhoods and who lives in them. It is possible for an MSA to have a considerable amount of economic residential segregation but have few affluent neighborhoods and few affluent households living in them. In this study, the concentration of affluence is measured as the percentage of affluent households in an MSA that live in affluent neighborhoods, the rate of concentrated affluence. This measure is similar to defining concentrated poverty as the percentage of the poor population living in high-poverty neighborhoods (Jargowsky 1997; Kasarda 1993). ${ }^{1}$

An affluent neighborhood is a census block group with a 1989 median household income at least four times the poverty rate for a four-person household in 1989 adjusted for MSA differences in the cost of living. In 1989, the weighted average poverty threshold for four-person households was $\$ 12,674$ (U.S. Bureau of the Census 1990); four times that is $\$ 50,696 .{ }^{2}$ Because no one has tried to identify affluent neighborhoods, there is no precedent for choosing a median household income of $\$ 50,696$ to identify block groups as affluent. ${ }^{3}$ This figure follows Smith's (1988) definition that a family is affluent if it has an income approximately four times the poverty level for a family of four. By focusing on median household income, this criterion defines a block group as affluent if half its households are affluent. It is consistent with research on the distribution of urban poverty that has classified census tracts on the basis of poverty rates and other indicators of low status (Jargowsky 1997; Kasarda 1993). This criterion for identifying affluent block groups is adjusted using cost-of-living indices for urban areas compiled by the American Chamber of Commerce Researchers Association (ACCRA 1989). ${ }^{4}$ From this point on, block groups identified as affluent are referred to as affluent neighborhoods. ${ }^{5}$

The next step in calculating rates of concentrated affluence for MSAs is to obtain counts of the affluent households in affluent neighborhoods and of the total number of affluent households. Households are defined as affluent if their income is greater than or equal to the median household income cutoff used to identify affluent neighborhoods. First, the number of affluent households in every neighborhood of an MSA is estimated. ${ }^{6}$ Then, the number of 
affluent households in an MSA in affluent neighborhoods is obtained by summing over all affluent neighborhoods, and the total number of affluent households in an MSA is obtained by summing over all neighborhoods. The rate of concentrated affluence is obtained by dividing the former by the latter and then multiplying by 100 .

There are shortcomings in this method for calculating the rate of concentrated affluence of which readers should be aware. Because census economic data are obtained from a sample, block group median household income is an estimate that sometimes is based on a small number of households. It is likely that this problem pertains equally to all MSAs, and it should appear in the analysis as measurement error that is randomly distributed across MSAs. Another shortcoming is that the use of a median household income of $\$ 50,696$ for identifying affluent neighborhoods and a household income of $\$ 50,696$ for identifying affluent households is arbitrary. This means caution should be exercised in examining actual rates of concentrated affluence. But because these cutoffs are applied equally to all MSAs, their arbitrariness should not be problematic for studying inter-MSA differences in concentrated affluence. Finally, because census household income distributions are not cross-classified by household size, there is no way to consider household size in identifying affluent households. It is assumed that household size by income is comparable across MSAs and that measurement error created by this problem is randomly distributed among them.

The rate of concentrated affluence also is calculated separately for whites and blacks using the method described above. An effort was made to separate Hispanic white household income distributions from non-Hispanic white household income distributions, so the rate of concentrated affluence for whites is for non-Hispanic whites. No such effort was made in calculating the rate of concentrated affluence for blacks. ${ }^{7}$

The independent variables are described in the order they appear in the analysis. Region of the country and the number of affluent households in an MSA are included throughout the analysis as control variables. Region is included to take into consideration broad ecological differences associated with the timing of development. For example, the concentration of affluence might be less in northeastern MSAs because many of their neighborhoods were built before the construction of economically homogeneous suburban developments was possible. The number of affluent households is considered because it places a structural constraint on the formation of affluent neighborhoods. The larger the number of affluent households, the larger the pool from which to form homogeneous affluent enclaves. Region is measured with three dummy variables for the Northeast, Midwest, and the South (MSAs in the West are the comparison group). The number of affluent 
households is measured with four dummy variables for MSAs with 10,000 to $24,999,25,000$ to $49,999,50,000$ to 149,999 , and 150,000+ affluent households (MSAs with less than 10,000 affluent households are the comparison group). When the analysis considers concentrated affluence separately for blacks and whites, the number of affluent households dummy variables is based on the number of affluent black and white households.

The economic characteristics of MSAs are measured with three variables that are indicators of the industry/occupation mix of the civilian employed population age $16+$. One is the percentage working in durable goods manufacturing, another is the percentage working in nondurable goods manufacturing, and the third is percentage working in professional, managerial, and technical occupations. ${ }^{8}$

Mean household income is calculated by dividing total household income in an MSA by the number of households. Income inequality is measured with the Gini concentration ratio. ${ }^{9}$ When the analysis considers the rate of concentrated affluence separately for blacks and whites, mean household income for blacks and whites and Gini concentration ratios for blacks and whites are calculated. ${ }^{10}$

The index of dissimilarity is used to measure economic residential segregation in MSAs - specifically, the segregation of affluent and nonaffluent households. Block groups are the geographic units on which the index is based. When the analysis examines the rate of concentrated affluence separately for blacks and whites, indices are calculated to measure segregation among affluent and nonaffluent black households and among affluent and nonaffluent white households. ${ }^{11}$

Two variables are included when the analysis considers the rate of concentrated affluence separately for blacks and whites that have no parallel in the analysis for the rate of concentrated affluence for the total population. These are two measures of racial residential segregation. One of these is the index of dissimilarity measuring residential segregation between blacks and whites, in general, and the second is the index of dissimilarity measuring residential segregation between affluent black households and affluent white households; block groups are the geographic units on which both indices are based. ${ }^{12}$

\section{RESULTS}

\section{LEVELS OF CONCENTRATED AFFLUENCE}

The analysis begins with some descriptive information about the concentration of affluence. This information should not be taken literally, given the 
TABLE 1: Metropolitan Areas with the Highest and Lowest Rates of Concentrated Affluence in 1990

\begin{tabular}{llll}
\hline \multicolumn{1}{c}{ Highest } & & \multicolumn{2}{c}{ Lowest } \\
MSA & Rate & \multicolumn{1}{c}{ MSA } & Rate \\
\hline Norwalk, CT & 63.3 & Beaver County, PA & 0.0 \\
Stamford, CT & 62.8 & Chico, CA & 0.0 \\
Lake County, IL & 55.9 & Eau Claire, WI & 0.0 \\
Danbury, CT & 49.8 & Glens Fall, NY & 0.0 \\
Newark, NJ & 45.4 & Hagerstown, MD & 0.0 \\
Washington, D.C. & 43.2 & Lawrence, KS & 0.0 \\
Anchorage, AK & 41.7 & Lewiston, ME & 0.0 \\
Anaheim, CA & 40.6 & Medford, OR & 0.0 \\
Dallas, TX & 40.2 & Pascagoula, MS & 0.0 \\
Houston, TX & 38.8 & Redding, CA & 0.0 \\
Midland, TX & 38.3 & St. Cloud, MN & 0.0 \\
Bergen, NJ & 38.3 & Sharon, PA & 0.0 \\
San Jose, CA & 37.5 & Sheboygan, WI & 0.0 \\
Middlesex, NJ & 37.3 & Steubenville, OH & 0.0 \\
Fort Worth, TX & 37.2 & Wheeling, WV & 0.0 \\
\hline
\end{tabular}

NOTE: MSA = metropolitan statistical area.

difficulties associated with identifying affluent neighborhoods and affluent households. However, it provides an introductory picture of the extensiveness of concentrated affluence and the types of MSAs in which it is greatest. By the methods employed, there were 14,782 affluent neighborhoods in U.S. MSAs in 1990, approximately $9 \%$ of all neighborhoods. Nearly 4 million affluent households lived in affluent neighborhoods, a rate of concentrated affluence of $24 \%$ for the country as a whole.

Table 1 shows the 15 MSAs with the highest and lowest rates of concentrated affluence. ${ }^{13}$ To help place the rates of concentrated affluence for these MSAs in perspective, the average rate for all 335 MSAs is 14.6, with a standard deviation of 11.4. Although the New York MSA does not appear among the MSAs with the highest rates of concentrated affluence (its rate is 23.0), several nearby MSAs do: Danbury, Connecticut; Newark, New Jersey; Bergen, New Jersey; Middlesex, New Jersey; Norwalk, Connecticut; and Stamford, Connecticut-the latter two with the highest rate of all (63\%). All 6 of these MSAs are part of the New York-Northern New Jersey-Long Island, NY-NJ-CT CMSA. Also included among the MSAs with the highest rates of concentrated affluence are Lake County, Illinois; Washington, D.C.; Anchorage, Alaska; Anaheim, California; San Jose, California; and the 4 Texas MSAs: Dallas, Houston, Midland, and Fort Worth. In contrast, 15 
MSAs have rates of concentrated affluence equal to 0 ; they have no neighborhoods identified as affluent. These MSAs have small populations, and many of them are located in states in which durable goods manufacturing is prominent.

Overall, there are not great differences in income inequality between the MSAs with the highest and lowest rates of concentrated affluence, an unexpected result. The average Gini concentration ratio for the 15 MSAs with the lowest rates of concentrated affluence is 0.42 , and it is 0.43 for the $15 \mathrm{MSAs}$ with the highest rates. For all $335 \mathrm{MSAs}$, the zero-order correlation between the rate of concentrated affluence and the Gini concentration ratio is a modest, though significant $(p<.01), 0.18$. There are, however, large differences in household income between the MSAs with the highest and lowest rates of concentrated affluence. The average mean household income for the 15 MSAs with the highest rates is $\$ 57,977$, including some with exceptionally high mean household incomes: Norwalk, Connecticut $(\$ 82,174)$ and Stamford, Connecticut $(\$ 96,804)$. Even Newark, New Jersey, which is frequently thought of for its poor inner-city population, has a mean household income of $\$ 55,448$. But for those with the lowest rates, the average is only $\$ 31,694$. For all $335 \mathrm{MSAs}$, the zero-order correlation between the rate of concentrated affluence and mean household income is 0.68 (significant, $p<.0001$ ). Controlling for mean household income, the partial correlation between the rate of concentrated affluence and the Gini concentration ratio increases to 0.27 (significant, $p<.0001$ ). Thus, even though income inequality is related to the concentration of affluence, as predicted, it appears that the economic characteristics of MSAs might influence the concentration of affluence more through the level of household income they generate than through the income inequality they produce.

\section{THE RATE OF CONCENTRATED AFFLUENCE}

Table 2 presents results providing a test of the hypotheses explaining differences among MSAs in the rate of concentrated affluence. In model 1, the rate of concentrated affluence is regressed on the region and number of affluent households dummy variables. None of the region dummy variables has a significant effect. But all of the affluent households dummy variables have significant positive effects. The greater the number of affluent households there are in an MSA, the higher the rate of concentrated affluence.

In model 2, variables measuring manufacturing employment and employment in professional, managerial, and technical occupations are added. Durable goods manufacturing does not have a significant effect, but nondurable goods manufacturing does; it is positive. Employment in professional, 
TABLE 2: Ordinary Least Squares Regression Analysis with the Rate of Concentrated Affluence for the Total Population as the Dependent Variable

\begin{tabular}{|c|c|c|c|c|c|c|c|c|}
\hline \multirow{2}{*}{$\begin{array}{l}\text { Independe } \\
\text { Region }\end{array}$} & \multicolumn{2}{|c|}{ Model 1} & \multicolumn{2}{|c|}{ Model 2} & \multicolumn{2}{|c|}{ Model 3} & \multicolumn{2}{|c|}{ Model 4} \\
\hline & & & & & & & & \\
\hline Northeast & -1.17 & (1.59) & $-3.02 *$ & (1.42) & $-4.67 * *$ & (1.24) & $-2.13^{*}$ & $(1.00)$ \\
\hline Midwest & 0.68 & (1.53) & 1.82 & (1.35) & $2.68^{*}$ & (1.17) & $1.97 *$ & $(0.94)$ \\
\hline South & 1.52 & (1.44) & $2.63 *$ & $(1.24)$ & $3.52 * *$ & (1.16) & $4.30 * *$ & $(0.92)$ \\
\hline \multicolumn{9}{|l|}{ Affluent households } \\
\hline $10,000-24,999$ & $6.67 * *$ & $(1.27)$ & $4.22 * *$ & $(1.08)$ & $2.80 * *$ & $(0.94)$ & 1.48 & $(0.76)$ \\
\hline $25,000-49,999$ & $11.32 * *$ & $(1.43)$ & $7.28 * *$ & $(1.23)$ & $3.97 * *$ & $(1.10)$ & $2.83 *$ & $(0.89)$ \\
\hline $50,000-149,999$ & $15.79 * *$ & $(1.58)$ & $10.87 * *$ & $(1.36)$ & $7.22 * *$ & $(1.22)$ & $4.01 * *$ & $(1.35)$ \\
\hline $150,000+$ & $25.06^{* * *}$ & (1.99) & $16.28 * *$ & (1.80) & $8.99 * *$ & (1.67) & $6.58 * *$ & (1.35) \\
\hline $\begin{array}{c}\% \text { Durable goods } \\
\text { manufacturing }\end{array}$ & - & - & -0.02 & $(0.08)$ & -0.07 & $(0.07)$ & 0.04 & $(0.06)$ \\
\hline $\begin{array}{l}\% \text { Nondurable goods } \\
\text { manufacturing }\end{array}$ & - & - & $0.34 * *$ & $(0.12)$ & 0.15 & $(0.11)$ & 0.12 & $(0.08)$ \\
\hline $\begin{array}{l}\% \text { Professional, } \\
\text { managerial, } \\
\text { technical } \\
\text { occupations }\end{array}$ & - & - & $1.38 * *$ & $(0.12)$ & $0.66^{* *}$ & $(0.12)$ & 0.24 & $(0.10)$ \\
\hline $\begin{array}{l}\text { Mean household } \\
\text { income }\end{array}$ & - & - & - & - & $0.001^{*}$ & $*(0.00)$ & $0.001 * *$ & $*(0.00)$ \\
\hline $\begin{array}{l}\text { Gini concentration } \\
\text { ratio }\end{array}$ & - & - & - & - & $54.67^{* *} *$ & (15.63) & -22.68 & (13.68) \\
\hline $\begin{array}{l}\text { Segregation } \\
\text { (affluent/ } \\
\text { nonaffluent) }\end{array}$ & - & - & - & - & - & - & $1.11 * *$ & $(0.08)$ \\
\hline Intercept & & 5.92 & & -29.31 & & -50.72 & & -57.49 \\
\hline Adjusted $R^{2}$ & & 0.39 & & 0.59 & & 0.69 & & 0.80 \\
\hline Number & & 335 & & 335 & & 335 & & 335 \\
\hline
\end{tabular}

NOTE: Unstandardized regression coefficients and standard errors in parentheses.

$* p<.05 . * * p<.01$.

managerial, and technical occupations also has a significant positive effect on the concentration of affluence. Except for the absence of an effect for durable goods manufacturing, these results are consistent with the hypothesis that affluence is most concentrated in metropolitan areas where the employment base reflects the economic restructuring associated with global finance.

Model 3 adds mean household income and income inequality (Gini concentration ratio) to model 2 . Both of these variables have significant positive effects. The more affluent the population is and the more unequal the distribution of income within the population, the greater the concentration of affluence. In an analysis not shown here, durable goods manufacturing, 
nondurable goods manufacturing, and professional, managerial, and technical employment all have significant positive effects on mean household income. However, surprisingly, only durable goods manufacturing has a significant effect on income inequality; it is negative as expected. Thus, durable goods manufacturing has both a positive effect on the concentration of affluence operating through mean household income and a negative effect operating through income inequality; these countervailing effects are responsible for the absence of an effect for durable goods manufacturing in model 2. On the other hand, nondurable goods manufacturing has only an indirect positive effect on the concentration of affluence operating through mean household income; it no longer has a significant effect in model 3. Finally, the positive effect of professional, managerial, and technical employment on the concentration of affluence largely is indirect through mean household income (its coefficient is more than halved between model 2 and model 3). Yet it retains a significant positive direct effect. Overall, these results show that MSA employment characteristics mainly influence the concentration of affluence through the level of income they generate, not by producing income inequality.

Residential segregation between affluent and nonaffluent households is added in model 4 . This variable has a significant positive effect as expected. The more segregated affluent households are from nonaffluent households, the higher the rate of concentrated affluence. It was expected that income inequality would have its effect on the rate of concentrated affluence through the economic segregation it created. This appears to be the case. In an analysis not shown here, income inequality has a significant positive effect on economic segregation. This translates into a positive indirect effect on the concentration of affluence. Furthermore, the coefficient for income inequality no longer is significant (and now it is even negative). Mean household income has a significant negative effect on economic segregation (analysis not shown). This yields a negative indirect effect on the concentration of affluence. In addition, mean household income continues to have a strong positive effect on the concentration of affluence when economic segregation is controlled. Clearly, the effect of mean household income on the concentration of affluence is from creating households with the income necessary for living in affluent neighborhoods, not from contributing to economic segregation. Finally, although it remains significant, the coefficient for professional, managerial, and technical employment is further reduced (by two-thirds) between models 3 and 4. In an analysis not shown, professional, managerial, and technical employment has a significant positive effect on economic segregation. Thus, this type of employment increases the concentration of affluence by contributing to economic segregation and by some mechanism 
unrelated to economic segregation and to the level of household income associated with it.

The effects of the region and the number of affluent households dummy variables change considerably from model 1 to model 4 . The coefficients for the number of affluent households dummy variables decrease drastically, although three of the four remain significant. Although it still appears that the number of affluent households in an MSA serves as a structural constraint on the formation of affluent neighborhoods, it also is apparent that the number of affluent households largely is a proxy for the economic characteristics of an MSA, the level of income and income inequality, and economic segregation. On the other hand, the coefficients for the region dummy variables increase in size between models 1 and 4 and become significant. Net of the other factors considered, MSAs in the Northeast have lower rates of concentrated affluence than MSAs in the West, and MSAs in the Midwest and South have higher rates. MSAs in the Northeast having lower rates of concentrated affluence is consistent with these MSAs having been built in an earlier era when it was more difficult to establish economically homogeneous affluent suburbs. But that this effect remains after economic segregation is controlled defies a ready explanation. MSAs in the Midwest and South having higher rates of concentrated affluence than those in the West, even though they tend to be older, also is difficult to explain.

\section{THE CONCENTRATION OF AFFLUENCE BY RACE}

Table 3 examines the rate of concentrated affluence separately for whites and blacks. The issue explored in this table is whether racial residential segregation affects the concentration of affluence for either group. Tailoring model 4 of Table 1 for whites and blacks, measures of residential segregation between affluent whites and blacks and between whites and blacks, in general, are added. The first column of Table 3 shows the effects of the segregation variables on the rate of concentrated affluence for whites. As predicted, segregation between affluent whites and blacks does not have an effect on the rate of concentrated affluence for whites, but segregation between blacks and whites, in general, does. The more segregated whites are from blacks, the greater the rate of concentrated affluence for whites. However, this effect is very modest, producing an increase in adjusted $R^{2}$ of only 0.01 over a model without it (not shown).

The second column of Table 3 repeats this analysis for blacks. ${ }^{14}$ For blacks, residential segregation between affluent whites and blacks has a significant negative effect on the rate of concentrated affluence, as expected. The greater the segregation between affluent blacks and whites, the lower the 
TABLE 3: Ordinary Least Squares Regression Analysis with the Rate of Concentrated Affluence for the White and Black Populations as the Dependent Variable

\begin{tabular}{|c|c|c|c|c|}
\hline \multirow{2}{*}{$\begin{array}{l}\text { Independent Variable } \\
\text { Region }\end{array}$} & \multicolumn{2}{|c|}{ Whites } & \multicolumn{2}{|c|}{ Blacks } \\
\hline & & & & \\
\hline Northeast & $-3.26 * *$ & $(1.25)$ & $-3.75 * *$ & * $(1.16)$ \\
\hline Midwest & 0.57 & (1.17) & 1.36 & $(1.25)$ \\
\hline South & $2.57 * *$ & $(1.25)$ & 1.12 & (1.19) \\
\hline \multicolumn{5}{|l|}{ Affluent households (w) ${ }^{\mathrm{a}}$} \\
\hline $10,000-24,999$ & 1.34 & $(0.81)$ & - & - \\
\hline $25,000-49,999$ & $2.51 *$ & (1.03) & - & - \\
\hline $50,000-99,999$ & $2.56^{*}$ & $(1.28)$ & - & - \\
\hline $100,000-149,999$ & $4.70^{* *}$ & (1.86) & - & - \\
\hline $150,000+$ & $6.15 * *$ & $(1.65)$ & - & - \\
\hline \multicolumn{5}{|l|}{ Affluent households (b) } \\
\hline $1,000-1,999$ & - & - & 1.29 & $(0.86)$ \\
\hline $2,000-4,999$ & - & - & 1.46 & $(0.81)$ \\
\hline $5,000-9,999$ & - & - & 1.57 & $(1.08)$ \\
\hline $10,000-19,999$ & - & - & 2.66 & $(1.50)$ \\
\hline $20,000+$ & - & - & 2.78 & $(1.58)$ \\
\hline$\%$ Durable goods manufacturing & 0.03 & $(0.10)$ & -0.03 & $(0.06)$ \\
\hline$\%$ Nondurable goods manufacturing & 0.12 & $(0.09)$ & 0.08 & $(0.08)$ \\
\hline$\%$ Professional, managerial, technical occupations & $0.33^{*}$ & $(0.11)$ & $0.33 * *$ & $(0.09)$ \\
\hline Mean household income (w) & $0.001 * *$ & $*(0.00)$ & - & - \\
\hline Gini concentration ratio (w) & $-50.13^{*}$ & $(20.01)$ & - & - \\
\hline Mean household income (b) & - & - & $0.001 * *$ & $*(0.00)$ \\
\hline Gini concentration ratio (b) & - & - & 14.13 & $(9.67)$ \\
\hline Segregation (affluent/nonaffluent) (w) & $1.13 * *$ & $(0.09)$ & - & - \\
\hline Segregation (affluent/nonaffluent) (b) & - & - & $0.24 * *$ & $(0.04)$ \\
\hline Segregation (affluent w/affluent b) & -0.03 & $(0.02)$ & $-0.12 *$ & $(0.05)$ \\
\hline Segregation (w/b) & $0.07 *$ & $(0.03)$ & 0.06 & $(0.05)$ \\
\hline Intercept & & -48.31 & & -34.06 \\
\hline Adjusted $R^{2}$ & & 0.81 & & 0.58 \\
\hline Number & & 335 & & 212 \\
\hline
\end{tabular}

NOTE: Unstandardized regression coefficients and standard errors in parentheses.

a. Excluded category is 0 to 9,999 affluent white (w) households.

b. Excluded category is 0 to 999 affluent black (b) households.

$* p<.05$. ** $p<.01$.

rate of concentrated affluence for blacks. On the other hand, segregation between blacks and whites, in general, has no effect on concentrated affluence among blacks. As was the case for whites, the effect of racial segregation is very modest, adding only 0.01 to the adjusted $R^{2}$ compared with the model not containing these variables (not shown). In summary, Table 3 
supports the hypothesis that racial residential segregation affects the concentration of affluence. The more whites are segregated from blacks, the greater the likelihood affluent white households live in affluent neighborhoods. And the more affluent black households are segregated from affluent white households, the less likely they are to live in affluent neighborhoods. However, racial segregation contributes very little, compared with other variables, to the rate of concentrated affluence for either blacks or whites.

The effects of the other variables in the model for whites are very similar to those found in Table 2 for the total population. One exception is that income inequality among whites has a significant negative effect after controlling for economic segregation (its effect is significant and positive before economic segregation is added; analysis not shown). That is, after taking into account that income inequality has a positive effect on the concentration of affluence for whites that operates through economic segregation, the white rate of concentrated affluence actually is lowest in those MSAs with the most income inequality. Generally, the effects of the other variables in the model for blacks also are similar to those obtained for the total population. An exception is that none of the dummy variables for the number of black affluent households has a significant effect. A possible explanation for this difference is that because black households are a small proportion of affluent households relative to white affluent households, characteristics among whites that lead to the formation of affluent neighborhoods might be more relevant to affluent blacks living in affluent neighborhoods than characteristics among blacks themselves.

To test this possibility (analysis not shown here), dummy variables for the number of white affluent households in an MSA were substituted for dummy variables for the number of black affluent households. Three of the dummy variables for the number of white affluent households (50,000-99,999, $100,000-149,999$, and 150,000+) have significant positive effects on the rate of concentrated affluence for blacks. Thus, it is true the concentration of affluence for blacks is more responsive to some characteristics pertaining to whites than to blacks.

\section{BLACK-WHITE DIFFERENCES IN CONCENTRATED AFFLUENCE}

In the last section of the analysis, black-white differences in the concentration of affluence are examined. ${ }^{15}$ The rate of concentrated affluence is higher for whites than for blacks. For all 335 MSAs, the mean rate of concentrated affluence for whites is 15.5 compared to 6.0 for blacks. Table 4 considers the possibility that racial residential segregation contributes to this 
TABLE 4: Ordinary Least Squares Regression Analysis with the Difference Between the White and Black Rates of Concentrated Affluence as the Dependent Variable

\begin{tabular}{lcc}
\hline Independent Variable & \multicolumn{2}{c}{ Model } \\
\hline Region & & \\
$\quad$ Northeast & -0.15 & $(1.46)$ \\
$\quad$ Midwest & -0.74 & $(1.51)$ \\
$\quad$ South & 1.59 & $(1.41)$ \\
Affluent households & & \\
$\quad$ 10,000-24,999 & 1.02 & $(1.04)$ \\
25,000-49,999 & 0.94 & $(1.18)$ \\
50,000-149,999 & 0.70 & $(1.29)$ \\
150,000+ & 2.27 & $(1.65)$ \\
\% Durable goods manufacturing & 0.04 & $(0.07)$ \\
\% Nondurable goods manufacturing & $0.30^{* *}$ & $(0.09)$ \\
\% Professional, managerial, technical occupations & $0.28^{* *}$ & $(0.13)$ \\
Mean household income (w) & $0.001^{* *}$ & $(0.00)$ \\
Mean household income (b) & $-0.001^{* *}$ & $(0.00)$ \\
Gini concentration ratio (w) & $-71.22^{* *}$ & $(22.32)$ \\
Gini concentration ratio (b) & 1.24 & $(11.24)$ \\
Segregation (affluent/nonaffluent) (w) & $0.98^{* *}$ & $(0.11)$ \\
Segregation (affluent/nonaffluent) (b) & $-0.25^{* *}$ & $(0.05)$ \\
Segregation (affluent w/affluent b) & $0.15^{* *}$ & $(0.06)$ \\
Segregation (w/b) & -0.06 & $(0.06)$ \\
Intercept & & -13.85 \\
Adjusted $R^{2}$ & & 0.76 \\
Number & & 212 \\
\hline
\end{tabular}

NOTE: Unstandardized regression coefficients and standard errors in parentheses. $\mathrm{w}=$ white; $\mathrm{b}=$ black.

$* p<.05 . * * p<.01$.

difference. In this table, the dependent variable is the difference between the rate of concentrated affluence for whites and the rate of concentrated affluence for blacks (white rate minus black rate).

Racial segregation does influence black-white differences in the rate of concentrated affluence. The effect of segregation between affluent blacks and whites is significant and positive. The more segregated affluent whites are from affluent blacks, the greater the difference between blacks and whites in the rate of concentrated affluence. On the other hand, segregation between blacks and whites, in general, does not have an effect. The effect of segregation, however, is relatively small compared to the effects of the other variables, adding only 0.01 to the adjusted $R^{2}$ compared to a model without these variables (analysis not shown). Differences between blacks and whites in mean household income make a strong contribution to black-white 
differences in the rate of concentrated affluence. The more income whites have, the greater the black-white difference in concentrated affluence; the more income blacks have, the smaller the difference. Alone, these two variables explain $57 \%$ of the variation in black-white differences in concentrated affluence (analysis not shown). Economic residential segregation among whites and among blacks also contributes to black-white differences in concentrated affluence. The more affluent whites are segregated from nonaffluent whites, the greater the black-white difference; the more affluent blacks are segregated from nonaffluent blacks, the less the difference. Controlling for economic segregation, income inequality among whites has a negative effect on black-white differences in concentrated affluence; net of other factors, the white rate of concentrated affluence tends to be lowest in the MSAs with the most white income inequality. Finally, employment in nondurable goods manufacturing and professional, managerial, and technical employment both have significant positive effects on black-white differences in concentrated affluence.

\section{HOUSEHOLD INCOME AND THE CONCENTRATION OF AFFLUENCE}

In this study, I have examined the concentration of affluence, the extent to which affluent households live in neighborhoods where at least half the neighboring households also are affluent, and differences between blacks and whites in the concentration of affluence. The concentration of affluence is one mechanism by which affluent households can pool the advantages of their affluence. To the extent white affluent households are more likely to live in affluent neighborhoods than black affluent households, they have greater access to this form of collective advantage.

A model for explaining intermetropolitan area differences in the concentration of affluence was developed and tested. This model posited that the level of concentrated affluence in a metropolitan area is a function of its employment base, the income inequality it produces, and the resulting economic residential segregation. Borrowing from the recent literature on economic restructuring, it was hypothesized that durable goods manufacturing employment would be accompanied by a low level of income inequality, low economic segregation, and low levels of concentrated affluence. Conversely, it was expected that nondurable goods manufacturing employment and employment in professional, managerial, and technical occupations would lead to high income inequality, high economic segregation, and high levels of concentrated affluence. 
In several respects, the results supported this model. Durable goods manufacturing is negatively related to income inequality, income inequality is positively related to economic segregation, and economic segregation is positively related to the concentration of affluence. But neither nondurable goods manufacturing nor professional, managerial, and technical employment are related to income inequality as they were predicted to be. Both of these types of economic activity, along with durable goods manufacturing, have strong positive effects on mean household income that, in turn, has a strong positive effect on the concentration of affluence, even when income inequality and economic residential segregation are controlled. Thus, it appears the employment base of a metropolitan area is mainly related to the concentration of affluence through the level of household income it produces, independent of the income inequality and economic residential segregation it generates. That is, a metropolitan area whose employment base produces a high level of income produces a population that is sufficiently affluent to enable affluent households to have access to affluent neighborhoods. This probably results from a combination of affluent households having enough income to be able to afford to live in affluent neighborhoods and there being enough affluent households available from which to create affluent neighborhoods. The data analyzed in this article pertain to the year 1990. That household income makes an important contribution to the concentration of affluence (and income inequality also plays a role through its effect on economic residential segregation) suggests there were significant increases in concentrated affluence in the 1990s, a period of sustained income growth and increasing income inequality (U.S. Bureau of the Census 2000a). Such a trend might have been abated, however, by stock market losses at the turn of the decade, significantly reducing the wealth of many affluent households.

When black-white differences in the concentration of affluence were examined, the focus was on the contribution of racial residential segregation. Based on the literature on black-white differences in residential returns to individual resources, it was hypothesized that racial residential segregation would enhance the concentration of affluence for whites and limit the concentration of affluence for blacks. Indeed, that is the case. Segregation between blacks and whites, in general, increases the concentration of affluence for whites, and segregation between affluent black and affluent white households decreases the concentration of affluence for blacks. In this way, segregation contributes to whites having a higher rate of concentrated affluence than blacks. However, racial residential segregation has a very modest effect on the rates of concentrated affluence for blacks and whites and to differences in them, compared with other variables, especially black and white mean household income. The strongest predictors of black and white rates of 
concentrated affluence are, respectively, black mean household income and white mean household income, and these two variables together are by far the strongest predictors of black-white differences in concentrated affluence. It appears that reducing racial residential segregation would do far less to reduce the disparity in access to affluent neighborhoods between affluent blacks and whites than would increasing black household income. The 1990s have seen increases in household income for blacks and for whites (U.S. Bureau of the Census 2000b). The increases for blacks probably have increased the concentration of affluence among blacks. But because white household income has increased in a parallel fashion, it is doubtful the black-white gap in concentrated affluence has closed. However, it is likely that both groups have grown in their geographic and, hence, social and cultural disconnection from those who are less fortunate.

\section{NOTES}

1. Massey and Eggers (1993) and Massey (1996) used the $P^{*}$ isolation index to measure the concentration of affluence. It is the exposure of affluent households to other affluent households within neighborhoods (the percentage of households that are affluent in the average affluent household's neighborhood). $\mathrm{P}^{*}$ is a global measure of economic residential segregation. It does not identify affluent neighborhoods or the number of affluent households that live in them. Except for when $\mathrm{P}^{*}$ has a very high value (which can only result if most affluent households live in neighborhoods where most of the neighboring households are affluent), it does not necessarily indicate anything about the propensity of affluent households to live in neighborhoods that are identifiably affluent. The value of the measure of concentrated affluence employed here is that it actually identifies affluent neighborhoods and the number of affluent households in them.

2. Block groups are used as proxies for neighborhoods for several reasons. Most research on economic residential segregation has used census tracts as proxies for neighborhoods. Census tracts have populations, on average, of around 4,000. Many affluent neighborhoods are in new suburbs where population density is low. Census tracts in such suburbs must be geographically large to maintain population size. Thus, the census tracts in the areas where many affluent households live include more territory than many people might consider neighborhoods. Block groups, with average populations of about 1,200 and geographically smaller, probably more closely approximate actual neighborhoods. Also, because they are smaller, block groups have more homogeneous populations, making it easier to identify small pockets of affluence.

3. Brooks-Gunn et al. (1993) measured neighborhood affluence as the fraction of families in a census tract with incomes more than $\$ 30,000$ using 1980 data. They did not, however, attempt to use family income to identify affluent neighborhoods.

4. The Cost of Living Index from the American Chamber of Commerce Researchers Association (ACCRA 1989) is based on items chosen to reflect the different categories of consumer spending. Weights assigned to categories of items are based on government survey data on expenditures for mid-management households. The cost-of-living indices calculated by the U.S. Bureau of Labor Statistics (BLS) were considered as an alternative. However, because the BLS makes calculations based on broad size and region categories, only making calculations for a 
small number of individual places, the BLS calculations hide a considerable amount of intermetropolitan variation in the cost of living.

5. To add validity to this criterion for identifying affluent neighborhoods, block groups so identified in two large metropolitan areas (750,000 to 1,000,000 in population) were visited. These block groups clearly display the outward appearance of affluence (large houses on well-maintained lots, expensive cars in driveways), and they are located in areas commonly considered affluent by people throughout the metropolitan areas. Thus, it is probable that the method employed here for identifying affluent neighborhoods performs reasonably well in identifying what most people have in mind as affluent neighborhoods.

6. Census data on household income show the number of households in income categories. The number of affluent households in each neighborhood of a metropolitan statistical area (MSA) is estimated by applying linear interpolation to the income category containing the cutoff and adding the number of affluent households in this category to the number of households in all higher income categories.

7. Block group household income distributions are available by race (white, black, Asian and Pacific Islander, Native American, and other race) and by ethnicity (Hispanic and non-Hispanic) but not simultaneously by race and ethnicity. This makes it impossible to directly estimate the number of affluent non-Hispanic black and non-Hispanic white households in affluent neighborhoods or in metropolitan areas. However, few people who reported their race as black in the 1990 census reported their ethnicity as Hispanic (nationally, a little over 2\%). Thus, the rate of concentrated affluence calculated from household income distributions for blacks pertains almost exclusively to non-Hispanic blacks. On the other hand, a larger number of people who reported their race as white in the 1990 census reported their ethnicity as Hispanic $6 \%$, nationally). Nearly all persons reporting Hispanic ethnicity in the 1990 census reported their race as white or other race (nationally, $52 \%$ and $43 \%$, respectively), and nearly everyone reporting their race as other reported their ethnicity as Hispanic (98\% nationally). Adding household income distributions for other race and for white households should include about $95 \%$ of Hispanic households. Then, subtracting household income distributions for Hispanics from combined white/other race household income distributions should result in household income distributions for a group that is almost exclusively non-Hispanic white. The rate of concentrated affluence for whites (presumably, non-Hispanic) is calculated from these distributions.

8. These occupations consist of three categories: executive, administrative, and managerial; professional specialty; and technicians and related support.

9. For the total population, metropolitan area household income distributions have 25 categories, the last being $\$ 150,000+$. To calculate the Gini concentration ratio, it is necessary to know the total income for all households in each income category. To estimate total income within the first 24 categories, the category midpoint was multiplied by the number of households in the category. Total income for all households with incomes of $\$ 150,000+$ is available for metropolitan areas. This figure was used as the total income for the last category.

10. Mean household income for blacks is calculated by dividing total black household income in a metropolitan area by the number of black households. The Gini concentration ratio for blacks is calculated using the nine-category household income distribution for blacks, capping the last category $(\$ 100,000+)$ at $\$ 150,000$ (data are unavailable by race-ethnicity on total income for households with incomes of $\$ 100,000+)$. Total income within each category is obtained by multiplying the midpoint of each category by the number of black households in the category. Mean household income for whites and the Gini concentration ratio for whites are calculated in a parallel manner but with an adjustment for Hispanics. That is, total white income is obtained by adding the total income for white and other race households and then subtracting the total income for Hispanic households, and the number of white households is obtained by adding 
the number of white and other race households and subtracting the number of Hispanic households. The Gini concentration ratio for whites uses the nine-category income distribution for white households obtained by adding together the income distributions for white and other race households and subtracting the income distribution for Hispanic households.

11. The number of affluent households in block groups (total, black and white) was determined in the process of calculating the rate of concentrated affluence. The number of nonaffluent households in block groups (total, black and white) is obtained by subtracting the number of affluent households from the total number of households.

12. For the latter index, the number of affluent black and white households in block groups is identified in the process of calculating the black and white rates of concentrated affluence.

13. For ease of presentation, MSAs are referred to by the city or county appearing first in the official MSA name.

14. Only the 212 MSAs with black populations of at least 10,000 are included in the analysis for blacks. Rates of concentrated affluence for blacks in MSAs with smaller black populations tend to be based on so few black affluent households that they are highly unstable.

15. This analysis is restricted to the 212 MSAs with black populations of at least 10,000 .

\section{REFERENCES}

Abramson, A. J., M. S. Tobin, and M. R. VanderGoot. 1995. The changing geography of metropolitan opportunity: The segregation of the poor in U.S. metropolitan areas, 1970-1990. Housing Policy Debate 6:45-72.

Alba, R. D., and J. R. Logan. 1991. Variations on two themes: Racial and ethnic patterns in the attainment of suburban residence. Demography 28:431-53.

-1993. Minority proximity to whites in suburbs: An individual-level analysis of segregation. American Journal of Sociology 98:1388-1427.

Alba, R. D., J. R. Logan, and P. E. Bellair. 1994. Living with crime: The implications of racial/ethnic differences in suburban location. Social Forces 73:395-434.

American Chamber of Commerce Researchers Association (ACCRA). 1989. Cost of living index. Vol. 23, issues 1-4. Louisville, KY: Author.

Brooks-Gunn, J., G. J. Duncan, P. K. Klebanov, and N. Sealand. 1993. Do neighborhoods influence child and adolescent development? American Journal of Sociology 99:353-95.

Danziger, S., and P. Gottschalk. 1995. America unequal. Cambridge, MA: Harvard Univ. Press.

Jargowsky, P. A. 1996. Take the money and run: Economic segregation in U.S. metropolitan areas. American Sociological Review 61:984-98.

- 1997. Poverty and place: Ghettos, barrios, and the American city. New York: Russell Sage.

Kasarda, J. D. 1993. Inner-city concentrated poverty and neighborhood distress: 1970-1990. Housing Policy Debate 4:253-302.

. 1995. Industrial restructuring and the changing location of jobs. In State of the union: America in the 1990s, edited by R. Farley, 215-68. New York: Russell Sage.

Krivo, L. J., and R. D. Peterson. 2000. The structural context of homicide: Accounting for racial differences in process. American Sociological Review 65:547-59.

Krivo, L. J., R. D. Peterson, H. Rizzo, and J. R. Reynolds. 1998. Race, segregation, and the concentration of disadvantage: 1980-1990. Social Problems 45:61-80.

Levy, F. 1995. Income and income inequality. In State of the union: America in the 1990s, edited by R. Farley, 1-58. New York: Russell Sage. 
Logan, J. R., and R. D. Alba. 1993. Locational returns to human capital: Minority access to suburban community resources. Demography 30:243-68.

1995. Who lives in affluent suburbs? Racial differences in eleven metropolitan regions. Sociological Focus 28:353-64.

Logan, J. R., R. D. Alba, and S. Leung. 1996. Minority access to white suburbs: A multi-regional comparison. Social Forces 74:851-81.

Logan, J. R., R. D. Alba, T. McNulty, and B. Fisher. 1996. Making a place in the metropolis: Locational attainment in cities and suburbs. Demography 33:443-53.

Maddrick, J. 1995. The end of affluence: The causes and consequences of America's economic dilemma. New York: Random House.

Massey, D. S. 1996. The age of extremes: Concentrated affluence and poverty in the twenty-first century. Demography 33:395-412.

Massey, D. S., and N. A. Denton. 1993. American apartheid: Segregation and the making of the underclass. Cambridge, MA: Harvard Univ. Press.

Massey, D. S., and M. L. Eggers. 1993. The spatial concentration of affluence and poverty during the 1970s. Urban Affairs Quarterly 29:299-315.

Morris, M., A. D. Bernhardt, and M. S. Hancock. 1994. Economic inequality: New methods for new trends. American Sociological Review 59:205-19.

Reich, R. B. 1989. As the world turns. The New Republic 200 (18): 23, 26-28.

Sassen, S. 1991. The global city: New York, London, Tokyo. Princeton, NJ: Princeton Univ. Press.

Smith, J. P. 1988. Poverty and the family. In Divided opportunities: Minorities, poverty and social policy, edited by G. D. Sandefur and M. Tienda, 141-72. New York: Plenum.

U.S. Bureau of the Census. 1990. Poverty in the United States: 1988 and 1989. Current Population Reports, Series P-60, No. 171. Washington, DC: Government Printing Office.

. 2000a. Historical income tables: Table H-3. Mean income received by each fifth and top 5 percent of households (all races): 1967-1999. Table H-4. Gini ratios for households, by race and Hispanic origin of householder: 1967-1999 [Online]. Available: www.census.gov/hhes/income/histinc

- 2000b. Historical income tables: Table H-3A. Mean income received by each fifth and top 5 percent of white households: 1967-1999. Table H-3B. Mean income received by each fifth and top 5 percent of black households: 1967-1999 [Online]. Available: www.census.gov/hhes/income/histinc

Wilson, W. J. 1987. The truly disadvantaged: The inner city, the underclass and public policy. Chicago: Univ. of Chicago Press.

1996. When work disappears: The world of the new urban poor. New York: Knopf.

Craig St. John is professor of sociology at the University of Oklahoma. His current research interests focus on economic and racial residential segregation. His most recent publication (with Robert Clymer), "Racial Residential Segregation by Level of Socioeconomic Status," appeared in the September 2000 issue of Social Science Quarterly. He also is studying volunteering in the aftermath of the 1995 bombing of the Murrah Federal Building in Oklahoma City. 